\title{
Growth of Pakistani children in relation to the 1990 growth standards
}

\author{
A M Kelly, N J Shaw, A M C Thomas, P B Pynsent, D J Baker
}

\begin{abstract}
This study was designed to compare the growth of Pakistani schoolchildren in the UK with the 1990 UK growth standards. Measurements of height, weight, and sitting height were performed on 785 Pakistani schoolchildren aged 5-14 years with the mean values for each age and sex being plotted on the UK growth standards. The results were expressed as SD scores relative to the 1990 reference data.

The mean height for the boys was only 0.2 SD scores below the mean for the new growth standards with the mean height for the girls being $0.4 \mathrm{SD}$ scores below the mean. The mean values for weight and body mass index were 0.3 and $0.5 \mathrm{SD}$ scores less than the mean for boys and girls respectively.

This study demonstrates that the growth of Pakistani schoolchildren in the UK is comparable to the 1990 UK growth standards with only minor differences. It is not safe to assume that short stature or low body weight in a Pakistani child is due to his or her ethnic background.

(Arch Dis Child 1997;77:401-405)
\end{abstract}

Keywords: growth; growth standards; Pakistani children

The 1990 UK reference charts are the most recent cross sectional growth standards for British children and were published in $1995 . .^{12}$ They are intended to replace the TannerWhitehouse charts, which were based on a comprehensive survey of the heights and weights of London County Council schoolchildren in $1959 .^{3}$ At that time, there were few children from ethnic minorities in the population and they were not specifically included in the survey. Since then the population profile has changed markedly as the number of children from ethnic minorities has increased. Currently, there are one million children in the West Midlands who are less than 15 years old and $14 \%$ of these are from ethnic minority groups. Those children whose families originate from the Indian subcontinent (hereafter referred to as Asian) form the largest group and account for almost $10 \%$ of all children in the region. ${ }^{4}$

The new growth standards have been compiled from data collated from seven separate growth studies, conducted in different areas of the UK between 1978 and 1990. Over 25000 children, mostly of white origin, were randomly selected and measured. Data from the non-white children were not used in the preparation of the charts because of the reported differences in growth and final height between ethnic groups and there were insufficient numbers to produce separate charts for each ethnic group. ${ }^{5-7}$ Body proportions also differ between ethnic groups but these differences are thought to be less dependent on environmental factors and more on genetic/ racial factors. ${ }^{8}$ The European and African child for instance has relatively longer legs than the Japanese.

This study was undertaken to accurately assess and compare the growth of present day schoolchildren from Pakistani families living in Birmingham with the new UK growth standards. This would confirm if the new growth standards derived from measuring white children could be applied to this ethnic group.

\section{Methods}

Altogether 785 children $(52 \%$ boys and $48 \%$ girls) aged 5-14 years, who attended one of the two chosen primary or secondary schools, were measured in September 1989 as part of an orthopaedic growth survey. The two schools were in the Saltley/Alum Rock area of Birmingham, which has been described as being one of the most deprived areas of Western Europe. These schools had the highest proportion of children eligible for free school meals in the city. Ninety three per cent of the children attending these schools were from families that had migrated from the Indian subcontinent and the majority came from a single area, Mirpur in north east Pakistan. Many of these families were effectively single parent households as the father was often absent in Pakistan.

Dates of birth of the children were noted from the school registers. All children aged from 4 years to 14 years 6 months were measured. Standing height, sitting height, and weight were recorded. A Holtain stadiometer was used for the standing height measurements using the stretched technique as described by Tanner and Whitehouse, the majority of which were recorded by a single observer (DJB). Sitting height was measured using a Harpenden sitting height table and weight with electronic scales.

Body mass index (BMI) was calculated from the height and weight data using the standard formula (BMI = weight in $\mathrm{kg} /$ height in $\mathrm{m}^{2}$ ). The mean values for standing and sitting height, leg length, weight, and BMI were calculated for each whole year group. For example, the year group of 5 year olds included children aged 4 years 7 months to 5 years 6 months. Data from children below the age of 4 
Table 1 Numbers of children in each age and sex group, age represented as decimal age

\begin{tabular}{lll}
\hline Age & Boys & Girls \\
\hline $4.6-5.5$ & 24 & 34 \\
$5.6-6.5$ & 37 & 33 \\
$6.6-7.5$ & 37 & 31 \\
$7.6-8.5$ & 45 & 35 \\
$8.6-9.5$ & 42 & 46 \\
$9.6-10.5$ & 50 & 40 \\
$10.6-11.5$ & 41 & 29 \\
$11.6-12.5$ & 53 & 45 \\
$12.6-13.5$ & 57 & 56 \\
$13.6-14.5$ & 22 & 28
\end{tabular}

years 7 months was not included because of small numbers. The means and 95\% confidence intervals for height and weight were plotted onto the 1990 nine centile growth charts for the appropriate sex. ${ }^{9}$ In addition using the computer package containing the raw data (Child Growth Foundation) it was possible to calculate $\mathrm{SD}$ scores for each age group in relation to the 1990 UK standards. A child on the 50th centile will have a SD score of 0 and a child on the 25 th centile a value of -0.67 . The mean values for BMI for each year group were calculated using the formula given above and these values and $95 \%$ confidence intervals plotted on the latest BMI reference charts, published in $1995 .^{2}$ The mean values for sitting height and leg length (standing height minus sitting height) were plotted on the existing Tanner-Whitehouse charts as no new reference data are available. ${ }^{10}$

\section{Results}

HEIGHT AND WEIGHT

The numbers of children in each age and sex group are shown in table 1.

The means and $95 \%$ confidence intervals for height relative to the 1990 reference data for boys are presented graphically (fig 1). The mean was on the 50th centile at the ages of 5, 6 , and 7 years. From 8 until 13 years the mean fell between the 25th and 50th centiles and returned to the 50th centile at 14 years. Overall, the mean height was only $0.2 \mathrm{SD}$ scores lower than that for white children. A different pattern was seen in the girls (fig 1) where apart from at the age of 5 years when the mean was on the 50th centile the mean was consistently between the 25th and 50th centiles. Overall the mean height for the girls was 0.4 SD scores less than that for white children.

The results for weight in the boys (fig 2) were similar to that obtained for height with the mean running close to the 50th centile until 9 years of age, when it fell to run between the
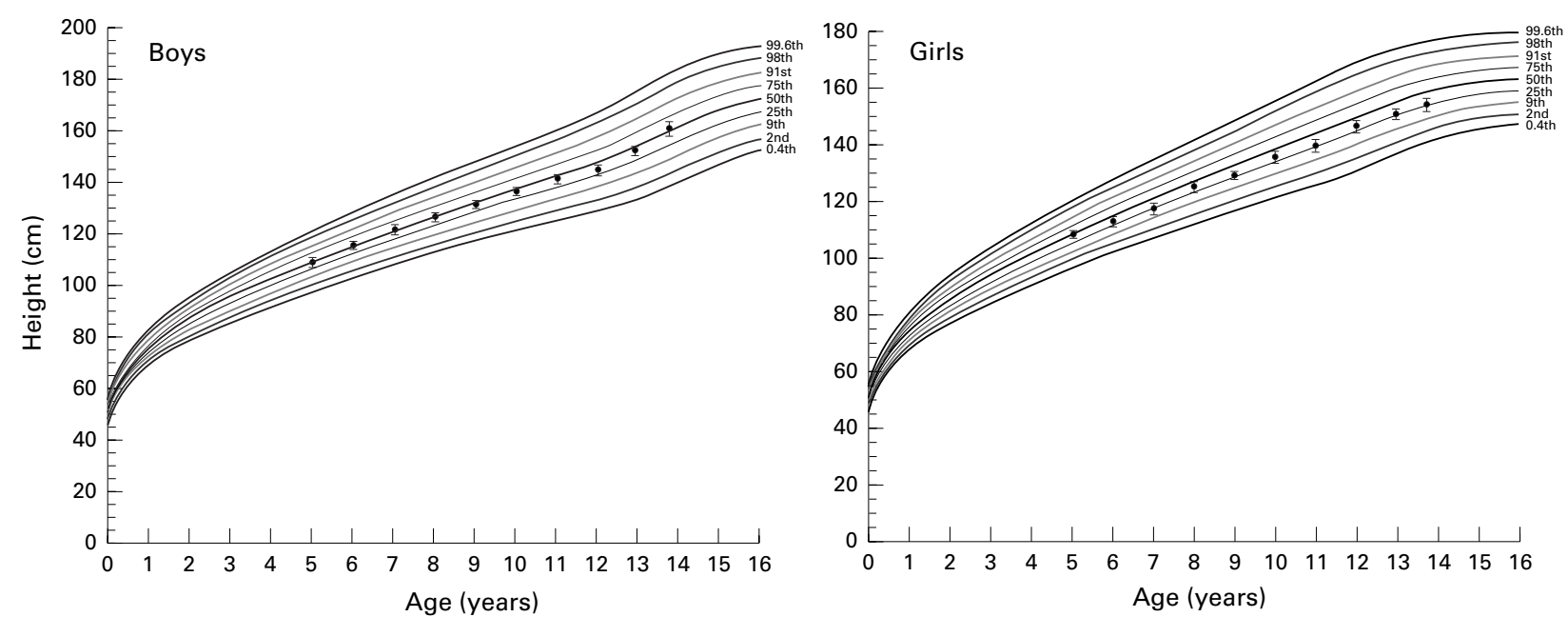

Figure 1 Height of Pakistani boys and girls aged 5-14 years in relation to the 1990 UK growth standards.
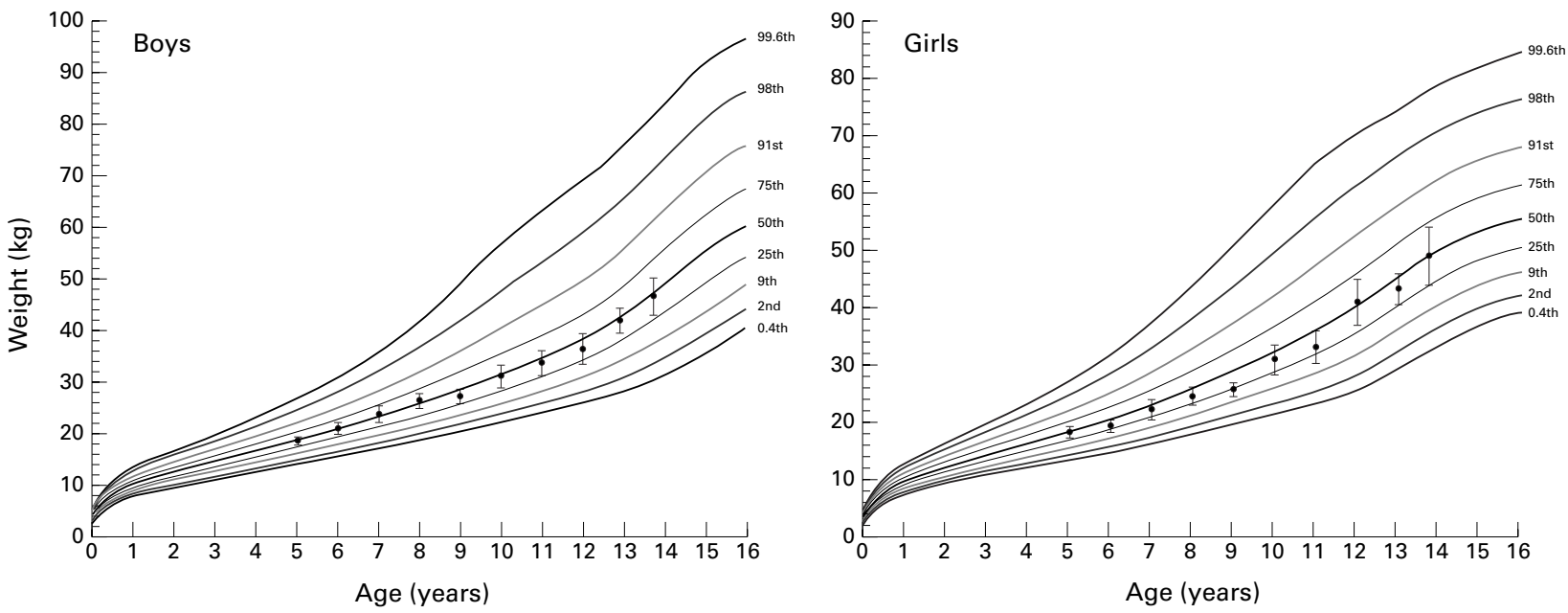

Figure 2 Weight of Pakistani boys and girls aged 5-14 years in relation to the 1990 UK growth standards. 

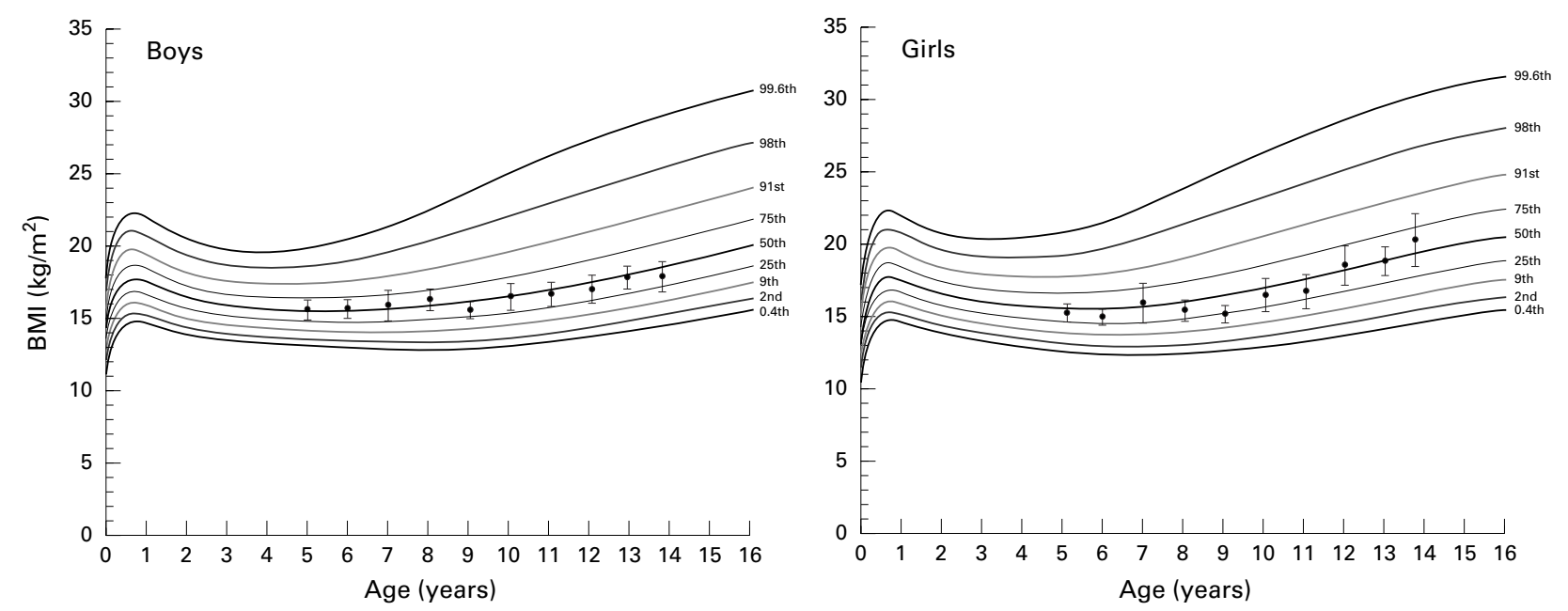

Figure 3 BMI of Pakistani boys and girls aged 5-14 years in relation to the 1990 UK growth standards.
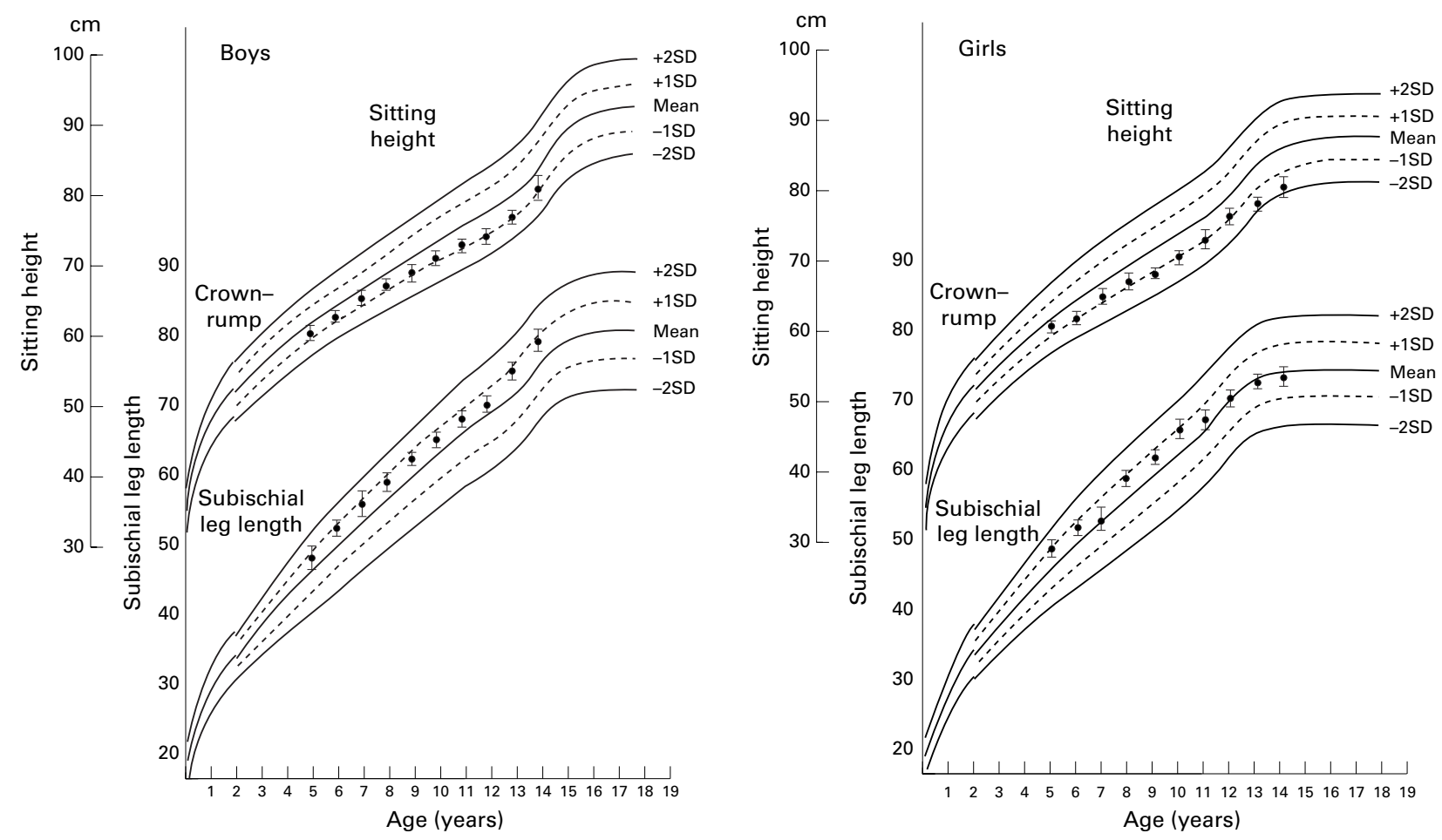

Figure 4 Sitting height and subischial leg length of Pakistani boys and girls in relation to the Tanner-Whitehouse standards.

25th and 50th centiles. Overall the mean weight was only $0.3 \mathrm{SD}$ scores less than for white boys. The picture was more variable in the girls (fig 2) with the mean weight between the 25 th and 50 th centiles until 9 years, when it fell below the 25 th centile and from 12 years onwards when it increased to run on or close to the 50th centile. Overall the mean weight was $0.5 \mathrm{SD}$ scores less than that for white girls.

BODY MASS INDEX

The results for BMI for boys and girls (fig 3) demonstrate that the curves were very similar to that obtained for weight alone except that the extreme points on the curve were more obvious. The mean values for boys were generally on or slightly above the 50th centile until 9 years when there was an obvious fall to almost the 25 th centile, before increasing to between the 25th and 50th centiles. Overall the difference was -0.4 SD scores.

The mean values for BMI in girls were between the 25 th and 50 th centiles between 5 and 8 years and fell to the 25th centile at 9 years. From 12 to 14 years the mean was above the 50th centile. Overall the SD score was -0.5 compared with white girls.

SITTING HEIGHT AND LEG LENGTH

Data on sitting height and leg length produced similar results for boys and girls (fig 4). The sitting height for boys consistently plotted between the mean and 1SD below the mean. In contrast, the leg length values consistently plotted between the mean and ISD above the mean.

The results for sitting height and leg length in girls were the same as the boys except that at 
13 and 14 years the sitting height was almost 2 SDs below the mean, and the corresponding leg lengths had fallen to the mean.

\section{Discussion}

Anecdotally, some paediatricians have believed that Asian children were shorter and lighter than their white counterparts and this difference may have been as much as one centile line (for example from the 50th to the 25th centile) on the old Tanner-Whitehouse chart. ${ }^{11}$ This belief may have affected rates of referral and investigation of short stature and failure to thrive in these children. There is some historical data comparing the growth of Asian children in their home countries with the Tanner-Whitehouse standards, which supports this view. Hauspie et al published a study in 1980 on the heights of children in West Bengal measured between 1952 and 1966, which found that the mean heights of both sexes were below the 10th centile. ${ }^{12}$ More recently, research in the UK by Rona et al as part of the National Study of Health and Growth, found that ethnic group was strongly associated with height in children living in inner city areas. ${ }^{5}$ The Afro-Caribbean children were the tallest, with the Gujerati and other Asian children being the shortest. These differences were not explained by social and biological variables. They concluded that the use of British growth charts for children from ethnic groups should be interpreted with caution.

Much depends on the classification of ethnic group as the accuracy with which this is done can produce vastly differing results. In a recent study by Gatrad et al, it was found that when the Asian group was divided both culturally and geographically, that Sikh children were unexpectedly taller than European children. ${ }^{11}$

In this study, data from only one particular ethnic group (Pakistani) were collected and compared with the 1990 reference charts produced from measuring white children. These charts have centile lines that are 0.67 SD scores apart. ${ }^{9}$ The results show that the Pakistani schoolchildren were only slightly shorter and lighter than their European counterparts, with the difference being 0.3 of a SD for boys and slightly more than this for girls. It has recently been suggested that when plotting the growth of children of Indian subcontinent origin on the new UK growth standards the height and weight charts should be shifted down by one centile line. ${ }^{13}$ Our data would indicate that this would be too large an adjustment for this particular ethnic group and only the weight and $\mathrm{BMI}$ in the girls would require an adjustment of this magnitude. The fact that the sample used in this study came from a deprived background would suggest that children from this ethnic group in better socioeconomic circumstances would have very similar growth patterns to those in the UK standards.

Growth performance has been found to be similar for children belonging to the same ethnic group living in comparable environments around the world. A longitudinal study of 1100 children in Pakistan from a high socioeconomic background between 1978 and 1988, found

\section{Key messages}

- Growth of Pakistani children in the UK is comparable to the 1990 UK standards

- A significant secular trend in growth in this group must have occurred

- Short stature in an Asian child may not be due to ethnic origin

that in both sexes the growth curves overlapped the National Center for Health Statistics (NCHS) of the USA which were used as comparison. ${ }^{1415}$

It seems that the growth of Pakistani children under optimum conditions is comparable with the growth achieved by affluent Western populations. However there was a notable difference in that the mean height of the Pakistani children in this study fell off around puberty especially so in the girls. Their final heights may be further below the mean than the values at 14 years. The reasons for this include: that they are shorter than white girls prepubertally, their pubertal growth spurt is less marked, or puberty occurs later than average. The possibility of pubertal delay would be supported by the reduction in sitting height compared with leg length which was particularly seen in the 13 and 14 year old girls. This degree of disproportion has been noted to occur in children with constitutional delay in growth and puberty. ${ }^{16}$ This needs to be examined further in longitudinal studies where Pakistani and white children are measured and their pubertal status recorded throughout childhood and puberty until growth is completed.

How can the improvement in the growth of present day Pakistani children compared with that of the previous generation measured in the 1960s and 1970s be explained? It is likely to be due to a significant secular trend that may relate to better nutrition and living in a cleaner environment. This hypothesis is supported by a study in the USA on two groups of low income children over a 10 year period which demonstrated that there was no change in the growth pattern of the indigenous children, but the growth pattern of the refugee children from South East Asia improved dramatically with their height SD scores moving from -0.8 to -0.2 of NCHS standards. ${ }^{17}$

Because of this secular trend Pakistani children are likely to be taller and heavier than their parents and grandparents, mirroring a trend also seen in white British children who are maturing earlier and reaching a greater adult stature and weight. This effect has been seen in other ethnic groups such as the Japanese who emigrated to the USA. They increased in size until they were similar to their native American counterparts. ${ }^{18}$ The parental heights were not recorded in this study and so it is not possible to confirm that these children exceeded their midparental centiles.

BMI was used to provide a measure of the fatness of the children in this study. BMI has been used routinely as a measure of obesity in 
adults for the last 25 years. It is relatively new in paediatric practice, where skinfold thickness has conventionally been used. BMI has the advantage that it is easily calculated from the height and weight data alone. It rises steeply in infancy, falls during the preschool years, and then rises into adulthood. ${ }^{19}$

The BMI results on the children in this study did not suggest that they were particularly obese or thin. All the values fell around the 25 th -50 th centiles. The boys tended to be heavier in early childhood, with both mean weight and BMI close to the 50th centile. A drop occurred at 9 years, and from there onwards the boys become leaner. The girls conversely tended to become heavier with advancing age and as their height fell off in puberty the BMI rose above the 50th centile.

From the charts showing sitting height and leg length, it would initially appear that the Pakistani children in this study have very different body proportions with shorter backs and longer legs than their white peers. However, the original Tanner-Whitehouse charts were formulated over 30 years ago and the children were measured using an anthropometer. It may have overestimated the sitting height of the children measured as this discrepancy has also been noted in white children. ${ }^{20}$ This apparent difference in body proportions is likely to be due to artefact emphasising the importance of obtaining new standards for sitting height.

In conclusion, this study has shown that the growth of Pakistani schoolchildren is comparable with the new UK growth standards produced from measuring white children, with only slight differences overall in height, weight, and BMI. There is no need to develop a separate growth chart for this particular ethnic group. It is not safe to assume that short stature or low weight in a Pakistani child is due to his or her ethnic origin.
1 Freeman JV, Cole TJ, Chinn S, Jones PRM, White EM, Preece MA. Cross sectional stature and weight reference curves for the UK, 1990. Arch Dis Child 1995;73:17-24.

2 Cole TJ, Freeman JV, Preece MA. Body mass index reference curves for the UK, 1990. Arch Dis Child 1995;73: 25-9.

3 Tanner JM, Whitehouse RH, Takaishi M. Standards from birth to maturity for height, weight, height velocity, and weight velocity: British children, 1965. Arch Dis Child weight velocity:

4 Haskey J. The ethnic minority populations resident in private households - estimates by county and metropolitan districts of England and Wales. Popul Trends 1991;63:2235.

5 Rona RJ, Chinn S. National Study on Health and Growth: social and biological factors associated with height of children from ethnic groups living in England. Ann Hum Biol 1986;13:453-71

6 Rona RJ, Chinn S. National Study on Health and Growth: social and biological factors associated with weight for height and triceps skinfold of children from ethnic groups living in England. Ann Hum Biol 1987;14:231-48.

7 Eveleth PB, Tanner JM. World wide variations in human growth. IPB Programme 8. London: Cambridge University Press, 1976.

8 Tanner JM. Population differences in body size, shape, and growth rate. A 1976 view. Arch Dis Child 1976;51:1.

9 Cole TJ. Do growth charts need a facelift? BMF 1994;308: 641-2.

10 Tanner JM, Whitehouse RH. Standards for sitting height and subischial leg length from birth to maturity: British children. Ware, Hertfordshire: Castlemead Publications, 1978.

11 Gatrad AR, Birch N, Hughes M. Preschool weights and heights of Europeans and five subgroups of Asians in Britain. Arch Dis Child 1994;71:207-10.

12 Hauspie RC, Das SR, Preece MA, Tanner JM. A longitudinal study of the growth in height of boys and girls of West Bengal aged six months to 20 years. Ann Hum Biol 1980;7: 429-41.

13 Chinn S, Cole TJ, Preece MA, Rona RJ. Growth charts for ethnic populations in UK. Lancet 1996;347:839-40

14 Akram DS, Agboatwala M. Growth parameters of Pakistani children. Indian f Pediatr 1991;58:825-32.

15 Hamill PVV, Dridzd T, Johnson CL, et al. Physical growth: National Center for Health Statistics percentiles. Am f Clin Nutr 1979; 32:607-29.

16 Albanese A, Stanhope R. Does constitutional delayed puberty cause segmental disproportion and short stature? Eur F Pediatr 1993;152:293-6.

17 Yip R, Scanlon K, Trowbridge F. Trends and patterns in height and weight status of low-income US children. Critical Reviews in Food Science and Nutrition 1993;33 (4/5):40921.

18 Hauspie RC, Vercauteren M, Susanne C. Secular changes in growth. Horm Res 1996;45 (suppl 2):8-17.

19 Hall DMB. Monitoring children's growth. BMF 1995;311: 583-4.

20 Herber SM, Milner RDG. Sitting heights in Sheffield, 1985: have standards changed? Acta Paediatr Scand 1987;76:81823. 